\title{
Morphological study of variation in shape of coronoid process of mandible in dry human bone in Mahakaushal region
}

\author{
Kanwar R. ${ }^{1}$, Agrawal R. ${ }^{2}$ \\ ${ }^{1}$ Dr. Rajeshwari Kanwar, Assistant Professor, Department of Anatomy, Netaji Subhash Chandra Bose Medical College, \\ Jabalpur (M.P.), ${ }^{2}$ Dr. Ranjana Agrawal, Assistant Professor, Department of Anatomy, Gandhi Medical College, Bhopal, \\ M.P, India.
}

Corresponding Author: Dr. Ranjana Agrawal, Assistant Professor, Department of Anatomy, Gandhi Medical College, Bhopal (M.P.) Address- T-4, Villa Regency, Vijay Nagar, Lalghati, Bhopal. E-mail: ranjana4anvi@gmail.com

\begin{abstract}
Introduction: The coronoid process is present at the ramus of mandible bone. The coronoid process projects upwards and slightly forwards as a triangular plate of bone. The variations in shape of coronoid process may acts as anthropological markers, to assess different populations \& races. It may also be useful in forensic studies for determination of gender. With keeping above facts in mind, present study was planned. Material methods: The shape of the coronoid processes of both sides of 52 dry adult human mandibles ( 29 male and 23 female) were studied to classify the variations. The study was conducted in NSCB Medical College, Jabalpur. Three types of shapes were observed which are hooked, triangular and round shaped. Results: Triangular shape of coronoid process was present in $48.08 \%$ mandibles. It was of rounded shape in $19.23 \%$ mandibles. In $32.69 \%$ mandibles found hooked shaped. out of total 52 mandibles, in 29 belonging to male, triangular shape was found in $36.21 \%$, rounded shape in $22.41 \%$ and hooked shape was found in $41.37 \%$ mandibles. Out of remaining 23 mandibles which were of females, triangular shape was found in 63.04\%, rounded shape in $15.22 \%$ and hooked shape in $21.74 \%$ mandibles. Conclusion: In present study, it is found that hooked shape coronoid is more common in male mandibles and in females, most common shape is triangular. As, no study was done previously at shapes of coronoid process at Mahakaushal area, hence, present study may be useful for maxillofacial surgeons and forensic experts especially of Mahakaushal region.
\end{abstract}

Keywords: Coronoid process, Mandible bone, Hooked Shaped

\section{Introduction}

The coronoid process of the mandible projects upward and slightly forward as a triangular plate of bone. Its margins and medial surface give attachment to temporalis muscle [1]. Literature shows the variations in the shapes of coronoid process is classified into three types as hooked, triangular, and rounded [2].

The morphological variation in the shape of coronoid process may be due to the hereditary or functional changes and has a correlation with the way of attachment of temporalis muscle. Various scholars in their studies have noted different sequences of prevalence of shapes. Tanveer A et al [3], Nirmale et al [4] observed that triangular shape of coronoid process were most prevalent which were followed by hooked and rounded shapes respectively in their respective

Manuscript received: $10^{\text {th }}$ April 2018

Reviewed: $20^{\text {th }}$ April 2018

Author Corrected: $25^{\text {th }}$ April 2018

Accepted for Publication: $29^{\text {th }}$ April 2018 studies. Vipul et al [5], Sahithiet al [6], Shakya et al [7], Sudha et al. [2] and Pradhan et al. [8] have concluded that most common shape of coronoid process was triangular only in their studies also, but, it was followed by rounded and hooked shapes respectively. It is very useful for anthropological and forensic studies to know about the prevalence of shapes of coronoid process [7]. Although various studies are already done on the topic but, it is noticeable that different scholars came out with different pattern of shapes according to prevalence of the shapes of coronoid process. As study on the topic was never done before in the Mahakaushal region, there was a serious need of study to enable maxillofacial surgeons, anthropologistsand forensic experts of Mahakaushal region with knowledge of variation of shapes of coronoid process of mandibles in human. Accordingly, the study was planned and published in a scientific journal for a better circulation among the targeted readers. 


\section{Material \& Methods}

Place of Study: Study was carried out in the Department of Anatomy, Netaji Subhash Chandra Bose Medical College, Jabalpur (M.P.), India.

Sampling: Shape of the coronoid processes of 52(104 sides) dry adult human mandibles were studied out of which 29 (58 sides) were of males and 23(46 sides) were of females.

Inclusion Criteria: Only adult's mandibles were included in this study.

Exclusion Criteria: Mandibles with damages were excluded from the study to come out with exact results.

\section{Method}

Male and Female bones were differentiated by noting standard morphological features. Different shapes of coronoid process observed are triangular, rounded, and hooked.

The different shapes of coronoid process were compared for sexual dimorphism and difference on either side.

Statistical Method: Statistical analysis was also done through Chi-square test using IBM SPSS software on personal computer.

\section{Results}

Table-1: Incidence of various shape of coronoid process in total side with percentage.

\begin{tabular}{|c|c|c|c|c|c|c|c|c|c|}
\hline \multirow{2}{*}{ Type } & \multirow{2}{*}{ Shape } & \multirow{2}{*}{ Total } & \multirow{2}{*}{$\%$} & \multicolumn{2}{|c|}{ Bi lateral } & \multicolumn{4}{|c|}{ Unilateral } \\
\cline { 5 - 10 } & & & & Sides & $\mathbf{\%}$ & Right & Left & Total & \% \\
\hline $\mathbf{1}$ & Triangular & 50 & 48.08 & 38 & 76.00 & 8 & 4 & 12 & 24.00 \\
\hline $\mathbf{2}$ & Rounded & 20 & 19.23 & 8 & 40.00 & 3 & 9 & 12 & 60.00 \\
\hline $\mathbf{3}$ & Hook & 34 & 32.69 & 24 & 70.59 & 6 & 4 & 10 & 29.41 \\
\hline \multicolumn{2}{r}{ Total } & 104 & 100 & 70 & 67.31 & 17 & 17 & 34 & 32.69 \\
\hline
\end{tabular}

In present study it is observed that Triangular shape of coronoid process was present in 50 mandibles out of which, in $76 \%$ cases it was bilateral while in $24 \%$ cases it was unilateral. Hence, observation leads to the interpretation that triangular shape of is more commonly bilateral. In case of unilateral, eight coronoid processof right side were triangular (corresponding side have five rounded shaped \& three hook shaped coronoid process). It was left side in four mandibles (corresponding side have two rounded and two hook shaped process). It was of round shaped in 20 mandibles, out of which, in $40 \%$ cases it was bilateral mandibles and unilateral in $60 \%$ mandibles. In cases of unilateral side, it is present at three right and nine left side of mandible, The corresponding side of mandibles were two triangular shaped and one hooked shape in case of right side, whilein cases of left side, five were triangular and four were hooked shape coronoid process.

Remaining 34 mandibles were found hooked shaped, out of which, $70.59 \%$ mandibles were bilateral and in $29.41 \%$ mandibles it was unilateral (six were right $\&$ four were on left side mandible). In case of unilateral corresponding sides were four rounded \& two triangular in right sides and three triangular \&one rounded in left sides. On analyzing above data using Chi Square Test on IBM SPSS software it is observed that $\mathrm{X}^{2}$ is 8.66, "P" value is .0132 and hence, results are significant. The test is used betweenBilateral and unilateral among the shapes of the bone. It was found that higher percentage $(76 \%)$ of bilateral is triangular shape and about $71 \%$ in Hooked shaped. In rounded shape, percentage of unilateral is higher than bilateral. Overall results are significant.

Table-2: Gender wise distribution of various shape of coronoid process in total sides of mandibles and its percentage.

\begin{tabular}{|c|c|c|c|c|c|c|c|c|}
\hline \multirow{2}{*}{ Type } & \multicolumn{4}{|c|}{ Male (58) } & \multicolumn{4}{c|}{ Female (46) } \\
\cline { 2 - 10 } & \multicolumn{2}{|c|}{ Bilateral } & \multicolumn{2}{c|}{ unilateral } & \multicolumn{2}{c|}{ Bilateral } & \multicolumn{2}{c|}{ Unilateral } \\
\cline { 2 - 10 } & Sides & $\mathbf{\%}$ & Sides & $\mathbf{\%}$ & Sides & \% & Sides & \% \\
\hline Triangular & 14 & 24.14 & 7 & 12.07 & 24 & 52.17 & 5 & 10.87 \\
\hline Rounded & 6 & 10.34 & 7 & 12.07 & 2 & 4.35 & 5 & 10.87 \\
\hline Hook & 18 & 31.03 & 6 & 10.34 & 6 & 13.04 & 4 & 8.70 \\
\hline Total & 38 & 65.52 & 20 & 34.48 & 32 & 69.57 & 14 & 30.43 \\
\hline
\end{tabular}




\section{Original Research Article}

Out of total 52 (104 side) mandibles, 29 (58 sides) were of male. On analysis of male mandibles it was found triangular shaped in $36.20 \%$, rounded shape in $22.41 \%$ and hook shaped in $41.37 \%$ mandibles. On the other hand, while analyzing 23 (46 sides) female mandibles, triangular shape was found in $63.04 \%$, rounded shape in $15.22 \%$ and hook shaped in $21.74 \%$ mandibles.

Above table also revealed that percentage of Triangular Shape are higher in female than male and percentage are higher in male in Hooked \& Rounded shape compared to female.

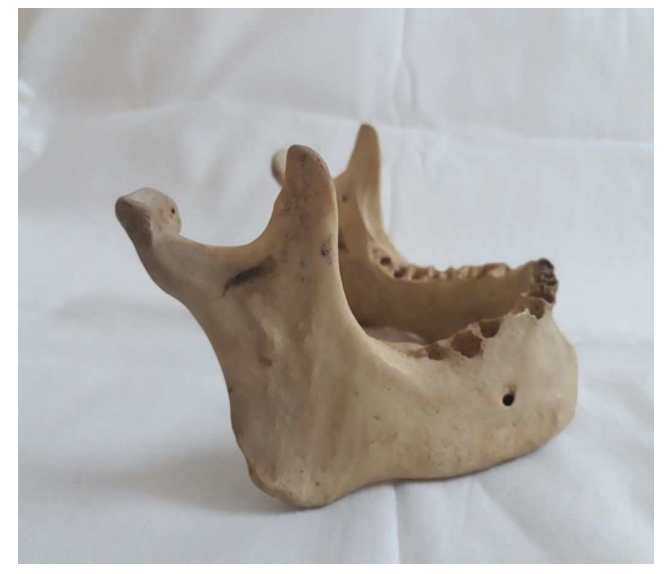

Photo-1: Hooked Shaped Mandible

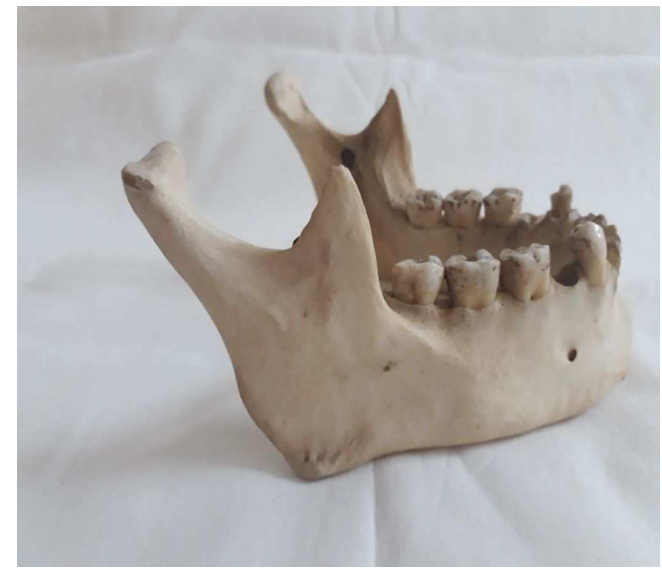

Photo-2: Triangular Shaped Mandible

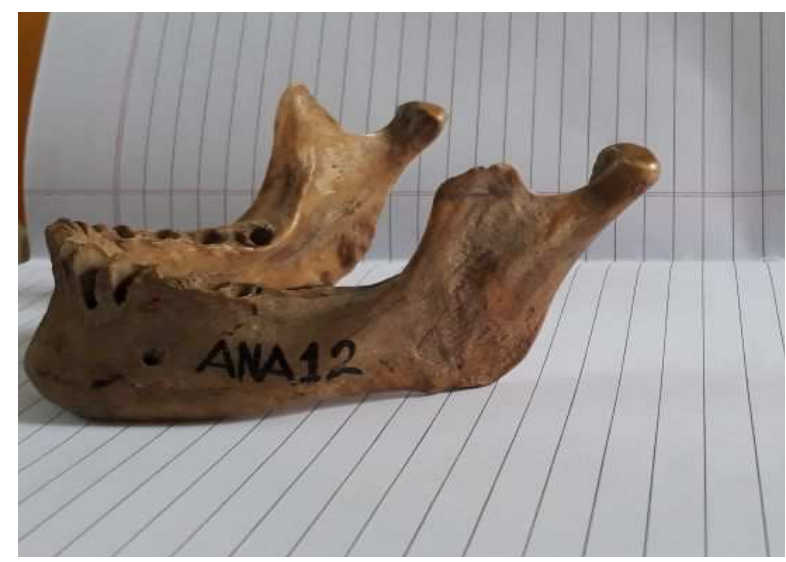

Photo-3: Rounded Shaped Mandible

\section{Discussion}

The knowledge of the morphological shapes of the coronoid process is useful for the maxillofacial surgeons. It makes an excellent donor graft site for reconstruction of orbital floor deformities. A Coronoid process graft can be used for alveolar defects repair, orbital floor repair, maxillary augmentation, repair of non-union fracture of mandible [9].

The present study exhibited overall triangular shape of coronoid process were most prevalent followed by hook shaped and rounded. As discussed earlier, it is observed that the patterns of prevalence of shapes in coronoid process of mandible in human were different in different studies. Some studies have shown triangular shape prevalence which is followed by rounded and hooked shape coronoid process respectively, while, some other studies have concluded triangular shape as most common shape of coronoid process, but, followed by hooked and rounded shapes respectively.

In the study of Tanveer A et al [3] and Nirmale et al [4] similar observations were found as in this study where triangular shape was followed by hooked and rounded shape respectively. In the study of Vipul et al [5] it was observed that triangular shaped are the most common shape but, Round \& Hook shapes are the next shapes respectively. According to Isaac B et al [10] in $79.6 \%$ mandibles the type of coronoid process was the same bilaterally and only $20.4 \%$ mandibles 
did the presentation differ between sides. Triangular and rounded types were the most and the least prevalent in males (46.5\% \& $23.5 \%$ respectively) while in female the triangular and hooked shape type were the most \& least prevalent $(53.5 \%$ \& $22.8 \%$ respectively)

According tothe studies conducted by Sahithi et al[6], Shakya et al [7], Sudha et al [2] and Pradhan et al [8]among the South Indian populations, in case of male and female,the most common shape of the coronoid process detected was triangular followed by round with male pre-dominancy. In their study Sheela D. Kadam et al [11] observed that most common shape of coronoid process was triangular in both sex (62.5\% in male and $67.08 \%$ in female). $87.26 \%$ mandible showing same shape coronoid process bilaterally and in $12.74 \%$ of mandible shape differs on both sides.

In present study it is found that triangular shape was more common in female $(63.04 \%)$ while hook shape of coronoid process is more common in male mandibles $(41.37 \%)$. However, the total share of these two shapes in total mandibles was $48.08 \%$ \& $32.69 \%$ in triangular and hooked shape respectively.

Table-3: Shapes of coronoid process in mandibles.

\begin{tabular}{|c|c|c|c|}
\hline \multirow{2}{*}{ Studty } & \multicolumn{3}{|c|}{ Shapes observed } \\
\cline { 2 - 4 } & Triangular & Hook Shaped & Rounded \\
\hline Issac B et al [10] & $49 \%$ & $27.4 \%$ & $23.6 \%$ \\
\hline Vipul et al [5] & $54.17 \%$ & $21.25 \%$ & $24.58 \%$ \\
\hline Nirmale et al [4] & $65 \%$ & $28 \%$ & $7 \%$ \\
\hline Tanveer A et al [3] & $67 \%$ & $30 \%$ & $3 \%$ \\
\hline Present Study & $48.08 \%$ & $32.69 \%$ & $19.23 \%$ \\
\hline
\end{tabular}

\section{Conclusion}

In present study it is found that hook shape of coronoid is most common in male mandibles followed by triangular and rounded shape. In case of female mandibles triangular shape is most common followed by hook and rounded shape.

For preoperative planning during reconstructive surgeries, knowledge of the morphological shapes of the coronoid process may be of great help for maxillofacial surgeons.

What Study add to existing knowledge: Study may be used by anthropologists to assess different populations $\&$ races and may also be useful for determination of gender by forensic expert.As shape of coronoid process depends on its functional use, it shows variation in different population groups. No studywas done previously at shape of coronoid process at population of Mahakaushal area; hence, present study may be very useful for maxillofacial surgeons, anthropologistsand forensic experts especially of Mahakaushal region. However, there is need of further study on larger group in this region.

Funding: Nil, Conflict of interest: None

Permission of IRB: Yes

\section{References}

1. Standring S. Skeletal system. In: William PL, Bannister LH, Barry MM, Collins P, Dussek IE, Fergusson MW, editors. Gray's Anatomy: The Anatomical Basis of Medicine and Surgery. 40th ed. New York: Churchill Living Stone; 2008. p. 532

2. Sudha R, Chandrasekaran S, Aruna N. Study of morphological variations in the shapes of coronoid process of mandible in South Indian population. IJCRR 2013;5:84-92

3. Khan TA., Sharieff JH. Observation on Morphological Features of Human Mandibles in 200 South Indian Subjects. Anatomica Karnataka, 2011; 5 (1) : 44-49

4. Nirmale VK, Mane UW, Sukre SB, Diwan CV. Morphological Features of Human Mandible. Int $\mathrm{J}$ of Recent Trends in Sci Technol. 2012; 3 (2): 38-43.

5. Prajapati VP, OjaswiniMalukar O, Nagar SK. Variations in the Morphological Appearance of the CoronoidProcess of Human Mandible. Nat J Med Res. 2011; 1(2): 64-66 
Original Research Article

6. Sahithi D, Reddy S, Teja DV, Koneru J, Praveen KN. Revealed the concealed-morphological variations of the coronoid process, condyle and sigmoid notch in personal identification. Egypt J Forensic Sci 2016; 6:108-13.

7. Shakya S, Ongole R, Nagraj SK. Morphology of Coronoid Process and Sigmoid Notch in Orthopantomogramsin South Indian Population. World J Dent. 2013; 4:1-3

8. Pradhan S, Bara DP, Patra S, Nayak S, Mohapatra C. Anatomical study of various shapes of mandibular coronoid process in relation to gender and age. IOSR J Dent Med Sci 2014;13(8):9-14.

9. Mintz S.M, Ettinger, A., Schmakel, T. and Gleason M.J. (1998) Contralateral coronoid process bone grafts for orbital floor reconstruction: An anatomic and clinical study. Journal of oral maxillofacial surgery 56 (10):1140-1145.

10. Priya R, Manjunath KY, Balasubramanyam. The varying shape of the coronoid process of the mandible. Indian J Dent Res. 2004 Jul-Sep;15(3):96-8.
11. Sheela D. Kadam, Priya P Roy, Ambali M.P, Doshi M A. VARIATION IN THE SHAPE OF CORONOI PROCESS IN DRY MANDIBLE OF MAHARASHTRA POPULATION. Int J Anat Res 2015; 3 (1): 895-898. DOI: 10.16965/ijar.2015.116.

12. Tapas S. Morphological variations of coronoid process in dry adult human mandibles. Indian J Basic Appl Med Res. 2014;3(2):401-405.

13. Hossain SM, Hossain SM, Banna FA. Variations in the shape of the coronoid process in the adult human mandible. Bangladesh J Anat2011;9:75-8.

14. Berry AC. Factors affecting the incidence of nonmetrical skeletal variants. J Anat. 1975 Dec;120(Pt 3): 519-35.

15. Reddy S, Rajesh N, Raghavendra MN, Alapati S, Kotha P. Unleash the unknown-frontal sinus and nasal septal patterns in personal identification. Int J Dent Sci Res 2014;2:141-5.

\section{How to cite this article?}

Kanwar R, Agrawal R. Morphological study of variation in shape of coronoid process of mandible in dry human bone in Mahakaushal region. Int J Med Res Rev 2018; 6(07):355-359. doi:10.17511/ijmrr.2018.i07.03. 